\title{
Multi-Fractal Characteristics of Daily Runoff Series of Weihe River Watershed
}

\author{
Baowen Yan ${ }^{1}$, Ankang Zhou ${ }^{2}$, Songbai Song1 \\ ${ }^{1}$ College of Water Resource and Architectural Engineering, Northwest A \& F University, Yangling, China \\ ${ }^{2}$ Water Conservancy Bureau of Ningqiang County, Ningqiang, China \\ Email: *ya nbaowen2000@163.com
}

How to cite this paper: Yan, B.W., Zhou, A.K. and Song, S.B. (2019) Multi-Fractal Characteristics of Daily Runoff Series of Weihe River Watershed. Journal of Water Resource and Protection, 11, 1146-1160. https://doi.org/10.4236/jwarp.2019.119067

Received: August 16, 2019

Accepted: September 8, 2019

Published: September 11, 2019

Copyright (c) 2019 by author(s) and Scientific Research Publishing Inc. This work is licensed under the Creative Commons Attribution International License (CC BY 4.0).

http://creativecommons.org/licenses/by/4.0/ (c) (i) Open Access

\begin{abstract}
Application of fractal theory on the evolution of nonlinear study of the hydrological system, which found its internal rules from the complex hydrologic system, could make us more fully understand the hydrodynamic characteristics of the complex motion of this system. Taking Weihe River as study area, this paper analyzes daily runoff series' multi-fractal character and relative fluctuation feature by using the De-trended Fluctuation Analysis (DFA) method. Result shows that the daily runoff series of main channel and branches of Weihe river all shows multi-fractal characteristics clearly, and the turns of multi-fractal intensity of daily runoff series in Weihe river are: Xianyang station (1.388) > Yingge station (0.697) > Linjiacun station (0.665) > Zhangjiashan station (0.662) $>$ Zhuangtou station (0.635). Rainfall, evaporation, water income and human activity and other factors affect the fluctuation character and multi-fractal intensity of daily runoff series through these factors' superimposition and pining down mutually. This study could provide a theoretical supply for obtaining the quantitative indicators on multi-fractal characteristics about eco-environment situation of watershed, and for runoff forecasting.
\end{abstract}

\section{Keywords}

Multi-Fractal, Daily Runoff, DFA, Weihe River Basin

\section{Introduction}

Runoff is one of key links of water cycle, its form and development affected by the comprehensive factors which include the climate, the terrain landform, soil and vegetation, so, describing it with multi-scales tool could be better, it may be used to well describe the fluctuation distributed condition of different partial 
conditions which influence to the entire series, and to analyze the function of influence factor to the small fluctuation. At present, in the outside and inside China, researches on runoff fractal mainly focus on the flood fractal characteristic. When Gupta and Waymire (1990) carried on the region analysis of flood, they successfully introduced the conception of scale invariable supposition, thus found a new way for the flood research [1]. In addition, carrying out the fractal characteristic research on the flood spatial distribution, and the research on affect factors to the flood spatial distribution is also very important aspect, this kind of research has also obtained many very new wonderful results [2] [3] (Bates et al. 1998; Robison and Sivapalan 1997). In recent years, fractal characteristic research of Chinese runoff's time series became a popular topic. Fu Jun et al. (1995) utilize fractal theory to study the river shape and current capacity process of Jialing River basin [4]. Wang Wensheng et al. (2005) utilized the boxes calculation method to disclose the fractal dimension of daily runoff process, furthermore to carry out the related analysis and the discussion, and, emphatically discussed the relationship between runoff process' fractal characteristic and the shape factors [5]. Ding Jing et al., Li Xianbin (1999) utilized the fractal theory on the seasonal flood, to do analysis on the linear fluctuation property, thus discovered that the flood season's current capacity process also shows fractal feature [6] [7]. Liu Xingpo et al. (2004) found that daily sewage capacity process also shows a fractal characteristic [8]. Yu Shuping et al. (2005) discussed the basin's ecology frail degree through taking process dimension as coefficient, thus established a foundation for carrying out the research on the relation between runoff process dimension and the ecological environment condition [9]. Chen Lajiao et al. (2006) aimed at the Malian River basin, also discussed the runoff fractal and the basin ecological environment relation [10]. But the runoff series' multiple fractal fluctuation characteristic research achieved not so much, only Yan Ai Ling (2007), Chen Ying et al. (2008) ever studied the daily runoff series' long distance relevance and the multiple fractal characteristics of Yangtze River and the Yellow River main channel [11] [12]. Chang Fuxuan (2011) utilized fractal theory to study daily rainfall series, daily runoff series, the flood series and rainstorm series' fractal feature and their difference [13]. Authors et al. (2011) also discussed the sole fractal characteristic of monthly runoff series of main channel and branches of Weihe River, tried to describe the hydrology system's non-linear complexity characteristic, but this river's multiple fractal characteristic research was not yet carried on [14].

The multiple fractal analysis ( $M F$ analysis) may calculate multiple fractal spectra $(M F$ spectrum), including the sole fractal dimension. Therefore, in carrying on analysis to the runoff succession's variation process, compared to sole fractal analysis, multiple fractal analysis may provide more information, and have the superiority in describing the non-homogenizing process. The correlation research indicated that daily runoff series can manifest the fluctuation degree of runoff process better. It is necessary to do the analysis on multiple fractal characteristics of daily runoff series of the branches and main channel of Weihe 
River, and further discuss the relationship between daily runoff process' multiple fractal and its fluctuation, provides a solid theoretical foundation for the runoff research and the forecast.

\section{Theory and Methods}

\subsection{Theory of Multiple Fractal}

Multiple fractal can also be called multiple scale fractal or multiple fractal measurement, multiple fractal may define initially as:

Supposes $R^{d}$ is a $d$ dimension Euclidean space or Metric space, $X$ is a $d$ dimension subset of $R^{d}$, and is also a measurement subset, or an invariant set of a dynamic system. To do appropriate division to $X$ and entrusts with the invariable measure $\mu_{0}$, supposes $\alpha$ is a related parameter closely with division, after $n$ steps' division, an obtained subset could be defined as $X_{n}(\alpha)$, if $X_{n}=\lim _{n \rightarrow \infty} X_{n}(\alpha)$ is a fractal set, then it could be called $(X, \mu)$ fractal subset. Under this division, fractal subsets produced from $(X, \mu)$ may express as co-fractal subsets of many fractal subsets, and each fractal subset has different fractal dimension, then this fractal set is multiple fractals.

\subsection{Multiple Fractal Non-Tendency Fluctuation Analysis Method}

Non-tendency fluctuation analysis method (DFA) is a time series' long period relevant method, Peng et al. (1994) proposed it when they research riptide behavior's machine-made process [15]. Kantelhardt et al. (2002) promote the DFA method using, and established a relation between it and multi-fractal formula system that based on the standard partition function, then they proposed multiple fractal non-tendency fluctuation analysis method (MF-DFA) could be used on studying the non-steady time series [16], this provided a new method for the multiple fractal spectrum estimation, and becomes firmly the effective method on the multiple fractal characteristic of the non-steady time series.

Concrete analysis process (Yuan Ying et al. 2007; Xie Xianhong et al. 2008) of Multiple fractal non-tendency fluctuation analysis method (MF-DFA) is shown as follows [17] [18]:

a) Accumulated deviation computation of time series. To a given time series $x_{t}(t=1,2, \cdots, N)$, the first operation is accumulated and transforms this series into a new series $Y(i)$ :

$$
Y(i)=\sum_{t=1}^{i}(x(t)-\bar{x}), \quad i=1,2, \cdots, N
$$

Here $\bar{X}$ is the average value of time series $x(t)$;

b) Former transformed new series $Y(i)$ has been divided into $n$ new subinterval opening with same steps, here $n=\operatorname{int}(N / s)$. As time series length $N$ maybe not a multiple time larger than the time length $s$, in order to enable the rear part remainder data could be effectively used, uses the similar method to deal with the reverse order series $Y(i)$, therefore may obtain $2 n$ equal length subintervals. 
c) Through fitting, each sub-sector's $(v=1,2, \cdots, 2 n)$ partial tendency could be obtained. Inner the subinterval, use least squares method to do $k$ steps multinomial data fitting on $s$ observation value, furthermore to look for the most superior fitting multinomial, then we can get partial tendency $P v(i)$.

$$
P v(i)=a_{0}+a_{1} i+a_{2} i^{2}+\cdots+a_{k} i^{k}
$$

Here: $a_{i}$ is the multinomial fitting coefficient $(i=1,2, \cdots, s) ; k$ is the most higher number of times of multinomial fitting, when $\mathrm{k}$ is $1,2,3, \ldots$ We call them separately $D F A 1, D F A 2, D F A 3, \ldots$.

d) To each sub-sector $v$, utilizes the multinomial come from fitting to eliminate the sub-partial tendency, then calculates each sub-sector's mean-square deviation to eliminate the tendency:

$$
\left\{\begin{array}{l}
F^{2}(v, s)=\frac{1}{s} \sum_{i}^{s}\{Y[(v-1) s+i]-P v(i)\}^{2}, \quad(v=1,2, \cdots, n) \\
F^{2}(v, s)=\frac{1}{s} \sum_{i}^{s}\{Y[N-(v-n) s+i]-P v(i)\}^{2}, \quad(v=n+1, n+2, \cdots, 2 n)
\end{array}\right.
$$

e) In order to enlarge or deduce the pantograph variance size to emphasized the fluctuation degree, to all same length sectors, look for their average $q(q \in R)$ steps DFA waving function

$$
\left\{\begin{array}{l}
F_{q} s=\frac{1}{2 n} \sum_{v=1}^{2 n}\left\{\left[F^{2}(v, s)\right]^{q / 2}\right\}^{1 / q}, q \neq 0 \\
F_{q} s=\exp \left\{\frac{1}{4 n} \sum_{v=1}^{2 n} \ln \left(F^{2}(v, s)\right)\right\}, \quad q=0
\end{array}\right.
$$

f) Determination of wave function scale coefficient. In each step $q$ s double logarithmic diagram $\left(s, F_{q} s\right)$, inspect wave function's scale behavior. If the long distance power law of primitive series $\left\{X_{t}\right\}$ is related, then here lies the power law relation between wave function $F_{q} s$ and the criterion $s$, namely:

$$
F_{q} s \sim s^{h(q)}
$$

To each division length s, may extract corresponding fluctuation function value $F_{q} s$, take slope ratio $h(q)$ that obtained from the linearity fitting value through least squares method, as $q$ steps generalized Hurst coefficient. When $h(q)$ is a constant and independent from $q$, the series shows as a sole fractal; When $h(q)$ is the function on $q$, the series should be the multiple fractal.

Another parameter could be used to mark the multiple fractal is the strange spectrum. Through MF-DFA, generalized Hurst coefficient $h(q)$ and Renyi coefficient $\pi(q)$ draw from multiple fractal formula system could be obtained. And following relation between the strange coefficient $\alpha$ and strange score $f(\alpha)$ exist here:

$$
\begin{aligned}
& \tau(q)=q h(q)-1 \\
& \alpha(q)=\frac{\partial}{\partial q} \tau(q)=h(q)+q h^{\prime}(q) \\
& f(\alpha)=q \alpha-\tau(q)=q[\alpha-h(q)]+1
\end{aligned}
$$




\section{Multi-Fractal Characteristics of Daily Runoff of Branches and Main Channel of Weihe River}

\subsection{Introduction of Weihe River Watershed}

Weihe River is the largest tributary of the Yellow River, China. It originated in the northern side of the Niaoshu Mountain, Gansu Province, the area of the watershed is $135,000 \mathrm{~km}^{2}$, length of the main channel is $818 \mathrm{Km}$, of which Shaanxi Province accounted for $61.4 \%$. The elevation of the watershed decreases from west to east, and changes from $329 \mathrm{~m}$ to $3495 \mathrm{~m}$. There are four main types of landforms in the basin: loess hills, loess plateaus, river valleys basin and Qinling mountains. The tributaries of the Weihe River are dense, Jinghe River and the Beiluohe River are the first and second major tributaries of it, both lie in the north area of the watershed. Other north tributaries include: Xianhe River, Sandu River, Hulu River, Niutou River, Qianhe River, Qishuihe River, Shichuanhe River, et al. On the south side, the larger tributaries include, the Bangshahe River, Jihe River, Shitouhe River, Heihe River, Fenghe river, and Bahe River (Figure $1)$.

\subsection{Data Selection}

Selects Linjiacun station, Xianyang station and the Huaxian station of the main channel, and Zhangjiashan station of Jinghe River (largest branch of Weihe River), Zhuangtou station of Beiluohe river and Yingge station of Shitouhe river as typical stations, use their daily runoff data series and through $M F-D F A$, to analyse their multiple fractal characteristic, at the same time, to discusses the fractal relationship between the branches' daily runoff process and main channel's daily runoff process, thus provide the data support for the complexity research of Weihe River basin's runoff process.

Among these stations, 58 year's daily runoff data (1944-2001) of Linjiacun, Zhangjiashan and Zhuangtou are selected, 23 years (1986-2008) of Xianyang station, Huaxian station, 48 years (1961-2008), Yingge station of Shitouhe river is 34 years (1974-2007).

\subsection{Determination of Multiple Fractal of Daily Runoff Process of Main Channel of Weihe River}

Using $M F-D F A$ method, to do the multiple fractal analyses on the daily runoff series of Linjiacun, Xianyang and Huaxian station. According to the requirement of multiple fractal research, determine the value of $s$ as 12, thus values of $q$ are $-12,-11, \cdots, 11,12$. To the exponent number $k$, takes it as $k=2,3,4,5$, then calculate Hurst coefficient $h(q)$ separately on three hydrologic station's daily runoff series. Results are shown in Table 1.

To $M F-D F A$ of 2 to 5 steps, the daily runoff process' Hurst generalized coefficient $h(q)$ of Linjiacun, Xianyang and Huaxian station are all not the constant number, also all changes along with $q$ 's changing (see Table 1 ), and $h(q)$ increased when step $k$ increased. It seems that their daily runoff series has the 


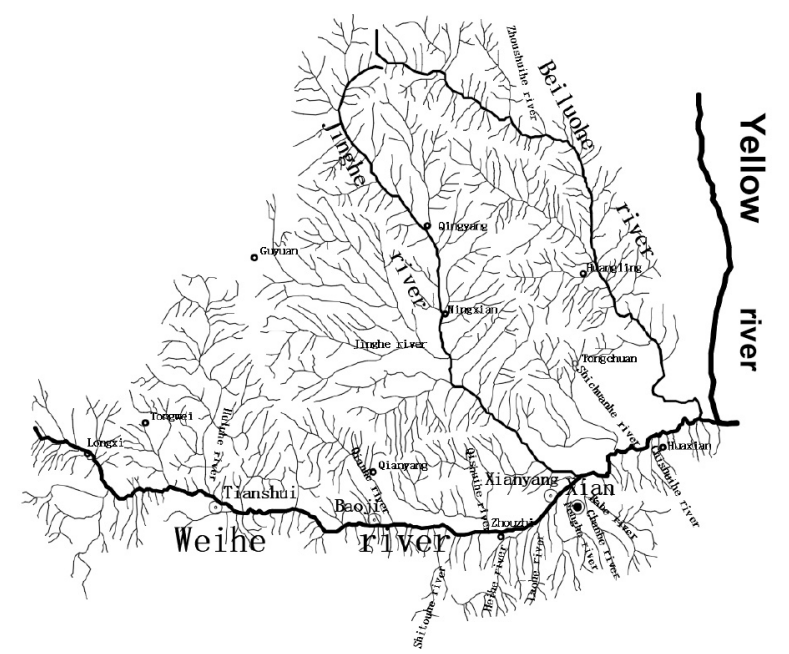

Figure 1. Geographic map of the Weihe River Watershed.

Table 1. $H(q)$ value of daily runoff on Lin Jiacun, Xianyang and Huaxian station in the Weihe River's main channel.

\begin{tabular}{|c|c|c|c|c|c|c|c|c|c|c|c|c|}
\hline \multirow{2}{*}{$\mathrm{q}$} & \multicolumn{4}{|c|}{ Lingjiacun station } & \multicolumn{4}{|c|}{ Xianyang Station } & \multicolumn{4}{|c|}{ Huaxian station } \\
\hline & $\mathrm{k}=2$ & $\mathrm{k}=3$ & $\mathrm{k}=4$ & $\mathrm{k}=5$ & $\mathrm{k}=2$ & $\mathrm{k}=3$ & $\mathrm{k}=4$ & $\mathrm{k}=5$ & $\mathrm{k}=2$ & $\mathrm{k}=3$ & $\mathrm{k}=4$ & $\mathrm{k}=5$ \\
\hline-12 & 1.58 & 1.583 & 1.586 & 1.641 & 1.973 & 2.067 & 2.099 & 2.148 & 1.386 & 1.462 & 1.524 & 1.601 \\
\hline-11 & 1.571 & 1.575 & 1.578 & 1.634 & 1.965 & 2.059 & 2.091 & 2.14 & 1.379 & 1.455 & 1.518 & 1.595 \\
\hline-10 & 1.56 & 1.565 & 1.569 & 1.625 & 1.955 & 2.049 & 2.082 & 2.13 & 1.371 & 1.448 & 1.511 & 1.587 \\
\hline-9 & 1.546 & 1.553 & 1.558 & 1.615 & 1.943 & 2.037 & 2.07 & 2.118 & 1.362 & 1.439 & 1.502 & 1.578 \\
\hline-8 & 1.528 & 1.538 & 1.544 & 1.601 & 1.928 & 2.022 & 2.056 & 2.104 & 1.35 & 1.428 & 1.491 & 1.567 \\
\hline-7 & 1.506 & 1.519 & 1.526 & 1.584 & 1.908 & 2.003 & 2.038 & 2.086 & 1.335 & 1.414 & 1.478 & 1.553 \\
\hline-6 & 1.477 & 1.494 & 1.502 & 1.561 & 1.883 & 1.979 & 2.015 & 2.062 & 1.316 & 1.397 & 1.461 & 1.535 \\
\hline-5 & 1.437 & 1.458 & 1.469 & 1.529 & 1.848 & 1.945 & 1.982 & 2.03 & 1.291 & 1.374 & 1.439 & 1.511 \\
\hline-4 & 1.379 & 1.406 & 1.421 & 1.481 & 1.797 & 1.896 & 1.936 & 1.984 & 1.256 & 1.342 & 1.408 & 1.478 \\
\hline-3 & 1.294 & 1.329 & 1.349 & 1.408 & 1.717 & 1.82 & 1.865 & 1.914 & 1.205 & 1.296 & 1.362 & 1.429 \\
\hline-2 & 1.168 & 1.214 & 1.241 & 1.295 & 1.584 & 1.694 & 1.749 & 1.799 & 1.131 & 1.226 & 1.292 & 1.355 \\
\hline-1 & 1.011 & 1.064 & 1.096 & 1.143 & 1.374 & 1.491 & 1.557 & 1.608 & 1.026 & 1.119 & 1.18 & 1.237 \\
\hline 0 & 0.857 & 0.903 & 0.935 & 0.978 & 1.131 & 1.23 & 1.292 & 1.333 & 0.897 & 0.968 & 1.021 & 1.068 \\
\hline 1 & 0.739 & 0.774 & 0.804 & 0.845 & 0.934 & 1.016 & 1.07 & 1.104 & 0.784 & 0.839 & 0.886 & 0.928 \\
\hline 2 & 0.666 & 0.693 & 0.723 & 0.764 & 0.806 & 0.887 & 0.943 & 0.975 & 0.706 & 0.755 & 0.802 & 0.844 \\
\hline 3 & 0.62 & 0.642 & 0.671 & 0.712 & 0.718 & 0.804 & 0.864 & 0.896 & 0.648 & 0.697 & 0.746 & 0.788 \\
\hline 4 & 0.589 & 0.607 & 0.635 & 0.676 & 0.655 & 0.747 & 0.81 & 0.843 & 0.605 & 0.655 & 0.705 & 0.748 \\
\hline 5 & 0.567 & 0.581 & 0.609 & 0.65 & 0.611 & 0.706 & 0.773 & 0.806 & 0.572 & 0.624 & 0.674 & 0.718 \\
\hline 6 & 0.552 & 0.562 & 0.589 & 0.629 & 0.578 & 0.677 & 0.746 & 0.779 & 0.546 & 0.6 & 0.651 & 0.695 \\
\hline 7 & 0.54 & 0.547 & 0.573 & 0.614 & 0.554 & 0.655 & 0.725 & 0.759 & 0.526 & 0.581 & 0.633 & 0.678 \\
\hline 8 & 0.53 & 0.535 & 0.56 & 0.601 & 0.535 & 0.638 & 0.709 & 0.744 & 0.51 & 0.566 & 0.619 & 0.664 \\
\hline 9 & 0.522 & 0.525 & 0.55 & 0.591 & 0.52 & 0.625 & 0.697 & 0.731 & 0.496 & 0.554 & 0.608 & 0.653 \\
\hline 10 & 0.516 & 0.517 & 0.542 & 0.582 & 0.508 & 0.614 & 0.687 & 0.721 & 0.485 & 0.544 & 0.599 & 0.644 \\
\hline 11 & 0.51 & 0.51 & 0.535 & 0.575 & 0.498 & 0.605 & 0.678 & 0.713 & 0.476 & 0.536 & 0.591 & 0.636 \\
\hline 12 & 0.505 & 0.505 & 0.528 & 0.569 & 0.49 & 0.598 & 0.671 & 0.706 & 0.468 & 0.529 & 0.585 & 0.63 \\
\hline
\end{tabular}

Here: $M F-D F A$ is called as $k$ steps method. 
similar non-linear relation, and $h(q)$ decreased along with increasing of $q$, thus shown as a digression function on $q$, namely, we can determine that the daily runoff process of Linjiacun, Xianyang and Huaxian station of Weihe River's main channel has multiple fractal characteristic.

\subsection{Multi-Fractal Characteristics of Daily Runoff Series of Weihe River's Tributaries}

Determination of multi-fractal of daily runoff process of Weihe River's tributaries, From Table 2, we can see that, to 2 steps' $M F-D F A$, when $q$ changes among - 12 and 12, branches' stations of Weihe River, include Zhangjiashan of Jinghe River, Zhuangtou of Beiluohe river and Yingge hydrologic station of Shitouhe river, their daily runoff series' generalized Hurst coefficient $h(q)$ are all not a constant, and all change along with the changing of $q$. All station's daily runoff series shows a similar non-linear relation, but $h(q)$ gradually reduced along with the increasing of $q$, display as the digression function on $q$, namely, daily runoff process of Zhangjiashan, Zhuangtou and Yingge stations also has multi-fractal character.

\subsection{Daily Runoff's Changing Law on $h(q)$ along with $k$ of Different Stations of Weihe River's Tributary Channels}

Making the $k$ step multinomial fitting to each sector's $s$ datum points of every runoff series of branches in Weihe River, aims of doing this lies on eliminating the $k$ step tendency fluctuation from the accumulation deviation series $y(i)$, and eliminating the $k-1$ step tendency fluctuation in the primitive series. Result shows in Table 2, when $q$ is certained, estimated value of generalized Hurst coefficient $h(q)$ of daily runoff series would increase along with the increasing of $q$ 's value in Zhangjiashan, Zhuangtou and Yingge station of Weihe River's branches.

In general, through analysis on the main channel and branches of Weihe river, when using different steps $M F-D F A$ to estimate runoff series' generalized Hurst coefficient $h(q)$, its value changes in different sizes, but the general tendency is same.

\section{Intensity of Runoff Series' Multi-Fractal of Weihe River's Main Channel and Branches}

Above research told us that, daily runoff series of main channel and branches of Weihe river all have multiple fractal feature, and all coefficients show the same changing rule. So, when carrying on analysis to multiple fractal intensity of runoff series of branches and main channel, it is a better choice to use daily runoff series' $k=2$ step multinomial (after eliminated tendency) to do contrast analysis.

\subsection{Difference on Multi-Fractal Intensity of Daily Runoff Series of Weihe River's Main Channel}

As to daily runoff series' multiple fractal intensities, we can generally use several 
Table 2. $H(q)$ value of daily runoff on Zhangjiashan, Zhuangtou and Yingge station in the tributary of Weihe River.

\begin{tabular}{|c|c|c|c|c|c|c|c|c|c|c|c|c|}
\hline \multirow{2}{*}{$q$} & \multicolumn{4}{|c|}{ Zhang Jiashan Station } & \multicolumn{4}{|c|}{ Zhuangtou Station } & \multicolumn{4}{|c|}{ Yingge Station } \\
\hline & $\mathrm{k}=2$ & $\mathrm{k}=3$ & $\mathrm{k}=4$ & $\mathrm{k}=5$ & $\mathrm{k}=2$ & $\mathrm{k}=3$ & $\mathrm{k}=4$ & $k=5$ & $\mathrm{k}=2$ & $k=3$ & $\mathrm{k}=4$ & $\mathrm{k}=5$ \\
\hline-12 & 0.843 & 0.898 & 0.975 & 1.063 & 0.83 & 0.892 & 0.95 & 1.047 & 1.002 & 1.114 & 1.233 & 1.356 \\
\hline-11 & 0.837 & 0.891 & 0.968 & 1.056 & 0.826 & 0.886 & 0.944 & 1.04 & 0.995 & 1.107 & 1.226 & 1.349 \\
\hline-10 & 0.829 & 0.883 & 0.96 & 1.047 & 0.82 & 0.879 & 0.936 & 1.032 & 0.987 & 1.099 & 1.219 & 1.341 \\
\hline-9 & 0.82 & 0.874 & 0.95 & 1.037 & 0.814 & 0.871 & 0.928 & 1.022 & 0.977 & 1.09 & 1.209 & 1.332 \\
\hline-8 & 0.81 & 0.862 & 0.937 & 1.024 & 0.807 & 0.862 & 0.917 & 1.01 & 0.965 & 1.078 & 1.198 & 1.32 \\
\hline-7 & 0.797 & 0.848 & 0.921 & 1.007 & 0.798 & 0.851 & 0.904 & 0.996 & 0.95 & 1.063 & 1.183 & 1.305 \\
\hline-6 & 0.78 & 0.829 & 0.9 & 0.984 & 0.788 & 0.837 & 0.889 & 0.977 & 0.929 & 1.044 & 1.164 & 1.287 \\
\hline-5 & 0.758 & 0.805 & 0.872 & 0.955 & 0.775 & 0.819 & 0.869 & 0.953 & 0.902 & 1.018 & 1.139 & 1.263 \\
\hline-4 & 0.729 & 0.774 & 0.837 & 0.918 & 0.759 & 0.797 & 0.844 & 0.923 & 0.864 & 0.984 & 1.106 & 1.23 \\
\hline-3 & 0.691 & 0.734 & 0.793 & 0.872 & 0.739 & 0.769 & 0.813 & 0.885 & 0.813 & 0.937 & 1.06 & 1.185 \\
\hline-2 & 0.645 & 0.687 & 0.743 & 0.816 & 0.712 & 0.736 & 0.776 & 0.84 & 0.748 & 0.878 & 1 & 1.124 \\
\hline-1 & 0.595 & 0.635 & 0.688 & 0.756 & 0.678 & 0.697 & 0.736 & 0.791 & 0.677 & 0.811 & 0.93 & 1.045 \\
\hline 0 & 0.548 & 0.583 & 0.635 & 0.698 & 0.639 & 0.655 & 0.692 & 0.74 & 0.609 & 0.74 & 0.856 & 0.96 \\
\hline 1 & 0.506 & 0.536 & 0.586 & 0.648 & 0.597 & 0.612 & 0.649 & 0.691 & 0.545 & 0.666 & 0.779 & 0.876 \\
\hline 2 & 0.469 & 0.497 & 0.546 & 0.61 & 0.557 & 0.572 & 0.608 & 0.646 & 0.476 & 0.586 & 0.7 & 0.793 \\
\hline 3 & 0.438 & 0.464 & 0.515 & 0.582 & 0.522 & 0.538 & 0.572 & 0.608 & 0.406 & 0.506 & 0.626 & 0.716 \\
\hline 4 & 0.411 & 0.437 & 0.491 & 0.561 & 0.491 & 0.511 & 0.544 & 0.579 & 0.345 & 0.438 & 0.564 & 0.655 \\
\hline 5 & 0.387 & 0.415 & 0.472 & 0.547 & 0.465 & 0.489 & 0.522 & 0.558 & 0.298 & 0.388 & 0.517 & 0.609 \\
\hline 6 & 0.367 & 0.397 & 0.457 & 0.536 & 0.443 & 0.472 & 0.505 & 0.542 & 0.262 & 0.35 & 0.482 & 0.575 \\
\hline 7 & 0.349 & 0.381 & 0.445 & 0.527 & 0.424 & 0.458 & 0.492 & 0.53 & 0.236 & 0.323 & 0.457 & 0.55 \\
\hline 8 & 0.333 & 0.368 & 0.445 & 0.521 & 0.409 & 0.447 & 0.481 & 0.521 & 0.216 & 0.302 & 0.437 & 0.53 \\
\hline 9 & 0.32 & 0.356 & 0.426 & 0.515 & 0.395 & 0.431 & 0.473 & 0.513 & 0.188 & 0.286 & 0.421 & 0.515 \\
\hline 10 & 0.309 & 0.347 & 0.419 & 0.51 & 0.384 & 0.431 & 0.466 & 0.508 & 0.188 & 0.273 & 0.409 & 0.503 \\
\hline 11 & 0.299 & 0.338 & 0.413 & 0.506 & 0.375 & 0.424 & 0.46 & 0.503 & 0.178 & 0.263 & 0.399 & 0.493 \\
\hline 12 & 0.291 & 0.331 & 0.407 & 0.503 & 0.367 & 0.419 & 0.455 & 0.499 & 0.17 & 0.254 & 0.39 & 0.484 \\
\hline
\end{tabular}

coefficients to determine, include change scope $\Delta h(q)$ of the generalized Hurst coefficient of $h(q)$, multiple fractal spectral widths $\Delta \alpha$, non-linear relation curve of scale coefficient $\tau(q)$ and $q$, as well as the changing relation curve of multiple fractal strange scores $f(\alpha)$ and the strange degree coefficient $\alpha$. Concrete judgment standard is: the bigger of $\Delta h(q)$ and $\Delta \alpha$, the bigger of multiple fractal intensity of corresponding runoff series; and the stronger of non-linearity on the $\tau(q)$ and $q$ s changing relation curve, the bigger of corresponding runoff series' multiple fractal intensity; And, in changing relation curve of multiple fractal strange scores $f(\alpha)$ and the strange degree coefficient $\alpha$, the bigger scope of the small fluctuation means the bigger multiple fractal intensity of runoff series. Among these, $\Delta h(q)$ could be calculated out directly, and $\Delta \alpha, \tau(q)$ 
and $f(\alpha)$ may obtain according to formula 6 , and calculated result of Linjiacun, Xianyang and Huaxian station of main channel of Weihe river are shown in Table 3.

At the main channel of Weihe River, $\Delta h(q)$ and $\Delta \alpha$ of Linjiacun station's daily runoff series is smaller than Xianyang station obviously (see Table 3), that means multiple fractal intensity of Linjiacun's daily runoff series is weaker than Xianyang station, at the same time, Huaxian station stands in the middle of these two stations, and its multiple fractal intensity weaker than Xianyang but stronger than Linjiacun station. Also Figure 2 tell us that $\tau(q)-q$ relation curve shows, non-linearity of Xianyang station's daily runoff series obviously stronger than Linjiacun station, and Huaxian station are stronger than Linjiacun but weaker than Xianyang station, namely, the judgment result is consistent when utilizing three coefficients on the daily runoff series' multiple fractal intensity at Weihe River's main channel station.

Figure 3 shows us the changing curve of multiple fractal strange scores $f(\alpha)$ along with $\alpha(q)$ of each station's daily runoff series. Multiple fractal strange scores $f(\alpha)$ of daily runoff series of three main channel stations are not asymmetrical, and the spectral line is right uncinus convex curve. Multiple fractal strange spectrum $f(\alpha)$ 's distributed sectors are different when $\mathrm{q}>0$ (correspondence smaller $\alpha$ ) and $q<0$ (correspondence bigger $\alpha$ ), while $q>0$, the multiple fractal strange spectra engraved the scale behavior of big fluctuation; As $q<0$, the multiple fractal strange spectra will describe the scale behavior of small fluctuation. Thus, the strange spectrum analysis result indicated that the influence of small fluctuation stands in a superior position in Weihe River main channel's daily runoff series, this is also the important reason why daily runoff series of Weihe River main channel have long distance relevant relation.

From Figure 3, occupied scope of small fluctuation of Xianyang station's daily runoff series obviously bigger than Linjiacun station, it means the Xianyang station daily runoff series' multiple fractal intensity is stronger than Linjiacune station, this is consistent with above judgment result from three methods.

\subsection{Difference on Multiple Fractal Intensity of Daily Runoff Series of Tributary of Weihe River}

To Weihe River's branches, $\Delta h(q)$ and $\Delta \alpha$ of daily runoff series of Yingge station at Shitouhe is bigger than Zhangjiashan station at Jinghe River obviously (Table 4), but $\Delta h(q)$ and $\Delta \alpha$ value of Zhangjiashan station, Jinghe river, and Zhuangtou, Beiluohe river's daily runoff series are almost same, namely,

Table 3. Multi-fractal fluctuations parameter of daily runoff' on Lin Jiacun, Xianyang and Huaxian station in the Weihe river.

\begin{tabular}{cccc}
\hline Station & Linjiacun & Xianyang & Huaxian county \\
\hline$\Delta h(q)$ & 1.07 & 1.48 & 0.92 \\
$\Delta \alpha$ & 1.23 & 1.66 & 1.08 \\
\hline
\end{tabular}


Table 4. Multi-fractal parameters of daily runoff series on Zhuangtou, Zhangjiashan and Yingge station in tributary of Weihe River.

\begin{tabular}{cccc}
\hline Stations & Zhangjiashan & Zhuangtou & Yingge \\
\hline$\Delta h(q)$ & 0.81 & 0.87 & 1.35 \\
$\Delta \alpha$ & 0.96 & 1.01 & 1.52 \\
\hline
\end{tabular}

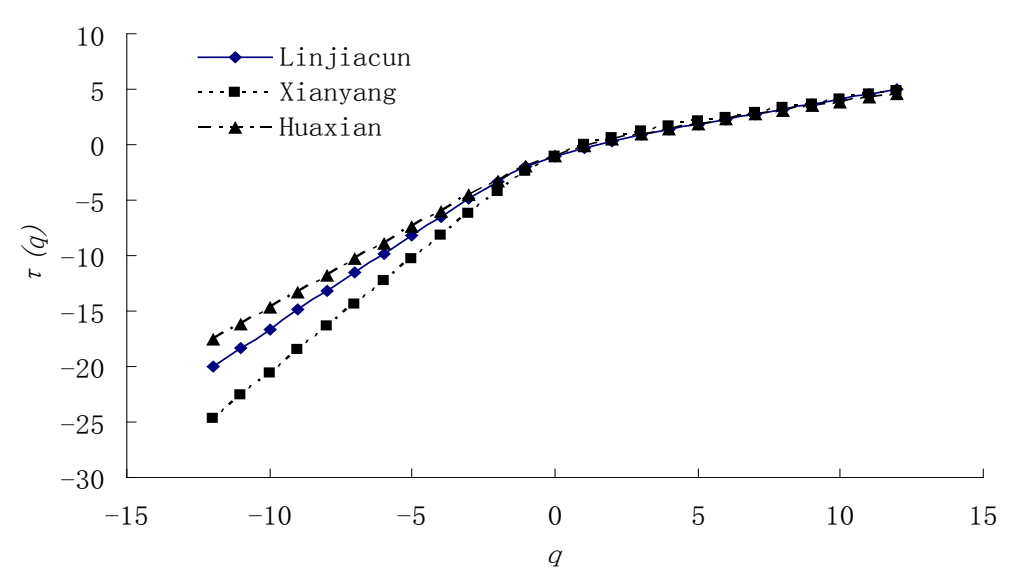

Figure 2. Variation relationship of daily runoff between $\tau(q)$ and $q$ on Linjiacun, Xianyang and Huaxian station in the Weihe River Basin.

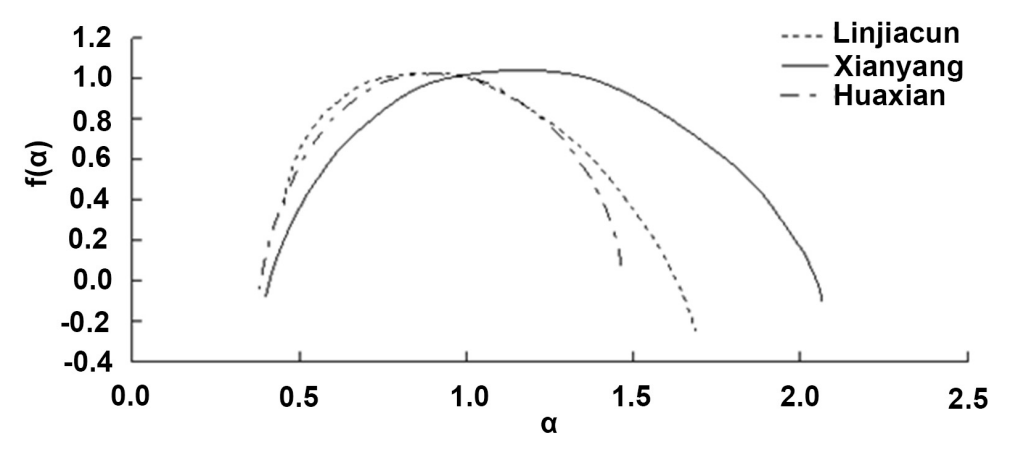

Figure 3. Changing curve of multi-fractal strange spectrum about daily runoff for $f(\alpha)$ on $\alpha$ in the three stations of main channel Weihe River.

multiple fractal intensity of daily runoff series of Shitouhe river is stronger than Jinghe river and Beiluohe river. Meanwhile from the changing relation curve of $\tau(q)$ along with $q$ in Figure 4, non-linearity of Yingge station's daily runoff series obviously stronger than other two stations, Zhangjiashan station in Jinghe river and Zhuangtou station in Beiluohe river, but the differences between Zhangjiashan and Zhuangtou is not very clear, it seems that this result is also same as that multiple fractal intensity judgment results come from three coefficients assessment methods.

From changing curve of multiple fractal strange spectrum $f(\alpha)$ along with $\alpha(q)$ on daily runoff series of each Weihe River's branch station (Figure 5), we can see that daily runoff series fractal strange scores $f(\alpha)$ of three Weihe River 's branches station are not asymmetrical, the spectral curve is the uncinus convex 


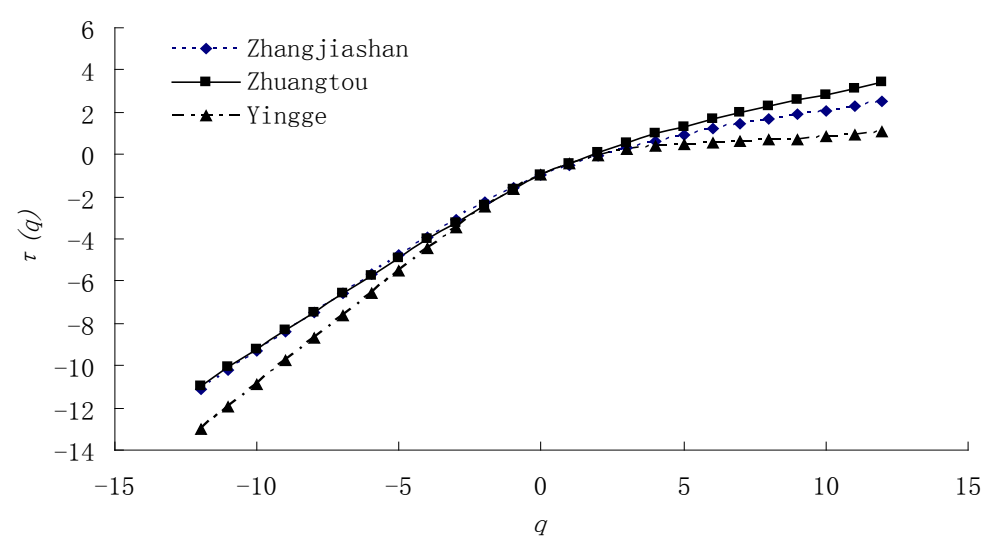

Figure 4. Diagram of daily runoff for $\tau(q)$ on $q$ about Zhangjiashan, Zhuangtou and Yingge stations in tributary of Weihe River.

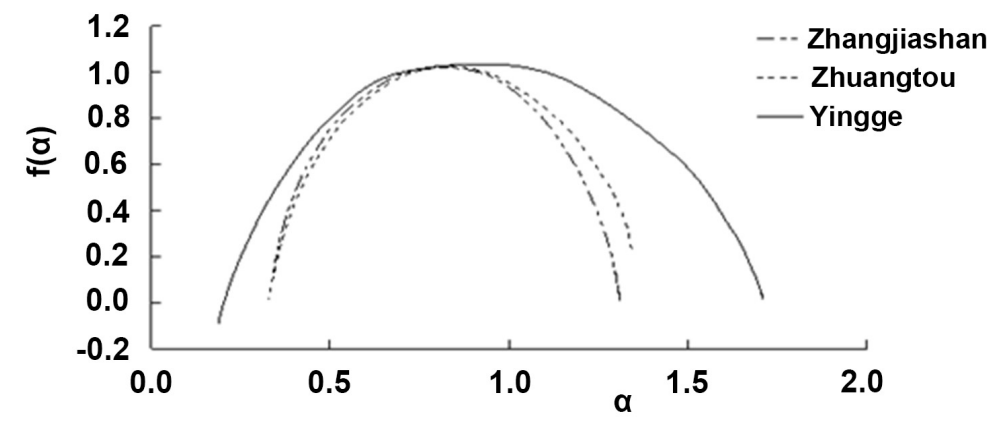

Figure 5. Changing curve of multi-fractal strange spectrum about daily runoff for $f(\alpha)$ along with $\alpha$ in three stations at tributary Weihe River.

curve and all turn towards right. This indicates that the small fluctuation's influence stands at the first place to Weihe River branches' daily runoff series, this also is one of the most important reasons of why Weihe River branches' daily runoff series have long distance relevant respectively. At the same time, in Figure 4, occupied scope of the small fluctuation of daily runoff series for Yingge station, Shitouhe river, is obviously bigger than Zhangjiashan and Zhuangtou stations, and Zhuangtou station is smaller slightly than Zhangjiashan station, but the difference is not big, namely, multiple fractal intensity of Yingge station's daily runoff series is bigger than that of Zhangiashan and Zhuangtou's, same as above three method judgment results.

\subsection{Multiple Fractal Intensity Contrast between Main Channel and Tributaries}

From the changing feature of strange spectral width $\Delta \alpha$ (Table $3 \&$ Table 4), we can find that daily runoff series' multiple fractal intensities of Xianyang station (1.388) at main channel is the strongest, and among other four stations, the difference is not so clear. In fact, we can get a turn of strange spectral width $\Delta \alpha$ of daily runoff series's multiple fractal intensities of Weihe river's main channel and tributaries stations, that is Xianyang station (1.388) > Yingge station 
$(0.697)>$ Linjiacun station $(0.665)>$ Zhangjiashan station $(0.662)>$ Zhuangtou station (0.635) this result also is consistent with the computation.

\section{Fluctuation Property Analysis of Main Channel and Tributary's Runoff Series of Weihe River}

Size of runoff series' multiple fractal intensity represented the runoff series' adulatory property, namely, the stronger of runoff series multiple fractality, the bigger of runoff series' adulatory property, and the greater of factor's change which could affect runoff process's fluctuation. This provided the research basis for studying effect degree of factors' changing to runoff fluctuation.

Multiple fractal strange scores $f(\alpha)$ along with $\alpha(q)$ 's change value of daily runoff series of each station could be obtained through fitting (Table 5). And it is obvious that in Figure 2 and Figure 4, the changing curve is the symmetrical bell shaped curve, its maximum value is 1 , this means the daily runoff series' extreme fluctuation value occupied a continual sector, and in this sector, various fluctuation could occur as possible as they can, and it has a same probability on the apparition of the big fluctuation and the small fluctuation.

\subsection{Fluctuation Property Analysis of up \& Downstream of Main Channel's Runoff Process}

Above analysis shows us that fluctuation degree of Xianyang station's runoff is the biggest one, the reason lies in that runoff process between Linjiacun station and Xianyang station strongly affected by water income and human activity, thus leading to the very fierce change, on the runoff fluctuation. But Huaxian station's runoff fluctuation is weaker than Linjiacun and Xianyang station, the reason is Huaxian station situate at downstream of main channel of Weihe River, many factors, such as rainfall, evaporation, water income from tributaries and human activity have an effect of interaction and adjustment each other, therefore cause the result of smaller runoff process fluctuation and tends to steadily.

\subsection{Fluctuation Property Analysis of Tributary's Runoff Process}

Similarly, the runoff series' fluctuation degree of Zhangjiashan station, Jinghe River and Zhuangtou station, Beiluohe river is almost same, but Shitouhe's runoff fluctuation degree is far bigger than above two stations. The reason lies in these facts, Zhangjiashan station place at Jinghe River, the biggest branch of Weihe river, and Zhuangtou station locate at Beiluohe river, the second big branch of Weihe river, controlled drainage area of these two hydrologic stations is big (occupying proportion of Weihe River drainage area is $33.7 \%$ and $20 \%$ respectively), factors that can affect their runoff's formation are many more, so adjustment ability of these two basins is relative strong. But Shitouhe river originates from Qinling mountain area, and its Yingge hydrologic station only has a rather small controlling drainage area, the runoff forms quickly, the mutual function's counterbalance among effect factors is also weak, so the factor's change shows a remarkable influence to runoff fluctuation. 
Table 5. Value of $\alpha$ and $f(\alpha)$ through fitting of each station at Weihe River.

\begin{tabular}{|c|c|c|c|c|c|c|c|c|c|c|}
\hline \multirow{2}{*}{$q$} & \multicolumn{2}{|c|}{ Lingjiacun } & \multicolumn{2}{|c|}{ Xianyang } & \multicolumn{2}{|c|}{ Zhangjiashan } & \multicolumn{2}{|c|}{ Zhuangtou } & \multicolumn{2}{|c|}{ Yingge } \\
\hline & $\alpha$ & $f(\alpha)$ & $\alpha$ & $f(\alpha)$ & $\alpha$ & $f(\alpha)$ & $\alpha$ & $f(\alpha)$ & $\alpha$ & $f(\alpha)$ \\
\hline-12 & 1.722 & 0.036 & 1.54 & 0 & 1.455 & 0.037 & 1.538 & 0.044 & 2.028 & 0.029 \\
\hline-11 & 1.72 & 0.053 & 1.54 & 0 & 1.453 & 0.054 & 1.536 & 0.063 & 2.027 & 0.044 \\
\hline-10 & 1.718 & 0.078 & 1.54 & 0.001 & 1.451 & 0.079 & 1.533 & 0.091 & 2.025 & 0.065 \\
\hline-9 & 1.714 & 0.113 & 1.54 & 0.002 & 1.447 & 0.114 & 1.529 & 0.13 & 2.022 & 0.097 \\
\hline-8 & 1.708 & 0.162 & 1.54 & 0.006 & 1.441 & 0.164 & 1.523 & 0.183 & 2.016 & 0.142 \\
\hline-7 & 1.699 & 0.23 & 1.539 & 0.013 & 1.432 & 0.232 & 1.513 & 0.254 & 2.008 & 0.206 \\
\hline-6 & 1.685 & 0.319 & 1.536 & 0.03 & 1.418 & 0.322 & 1.499 & 0.347 & 1.994 & 0.292 \\
\hline-5 & 1.664 & 0.434 & 1.529 & 0.068 & 1.397 & 0.436 & 1.478 & 0.462 & 1.974 & 0.406 \\
\hline-4 & 1.634 & 0.571 & 1.511 & 0.146 & 1.367 & 0.573 & 1.448 & 0.596 & 1.943 & 0.544 \\
\hline-3 & 1.591 & 0.72 & 1.467 & 0.298 & 1.324 & 0.721 & 1.407 & 0.739 & 1.898 & 0.699 \\
\hline-2 & 1.534 & 0.86 & 1.364 & 0.55 & 1.268 & 0.861 & 1.354 & 0.87 & 1.838 & 0.848 \\
\hline-1 & 1.465 & 0.962 & 1.157 & 0.851 & 1.199 & 0.962 & 1.29 & 0.965 & 1.763 & 0.959 \\
\hline 0 & 1.389 & 1.000 & 0.846 & 1.000 & 1.123 & 1.000 & 1.220 & 1.000 & 1.680 & 1.000 \\
\hline 1 & 1.312 & 0.962 & 0.536 & 0.851 & 1.048 & 0.962 & 1.15 & 0.965 & 1.596 & 0.959 \\
\hline 2 & 1.244 & 0.86 & 0.329 & 0.55 & 0.979 & 0.861 & 1.086 & 0.87 & 1.522 & 0.848 \\
\hline 3 & 1.187 & 0.72 & 0.225 & 0.298 & 0.923 & 0.721 & 1.033 & 0.739 & 1.462 & 0.699 \\
\hline 4 & 1.144 & 0.571 & 0.181 & 0.146 & 0.88 & 0.573 & 0.992 & 0.596 & 1.417 & 0.544 \\
\hline 5 & 1.114 & 0.434 & 0.163 & 0.068 & 0.85 & 0.436 & 0.962 & 0.462 & 1.386 & 0.406 \\
\hline 6 & 1.093 & 0.319 & 0.156 & 0.03 & 0.829 & 0.322 & 0.941 & 0.347 & 1.366 & 0.292 \\
\hline 7 & 1.079 & 0.23 & 0.154 & 0.013 & 0.815 & 0.232 & 0.927 & 0.254 & 1.352 & 0.206 \\
\hline 8 & 1.07 & 0.162 & 0.153 & 0.006 & 0.806 & 0.164 & 0.917 & 0.183 & 1.344 & 0.142 \\
\hline 9 & 1.064 & 0.113 & 0.152 & 0.002 & 0.8 & 0.114 & 0.911 & 0.13 & 1.338 & 0.097 \\
\hline 10 & 1.06 & 0.078 & 0.152 & 0.001 & 0.796 & 0.079 & 0.907 & 0.091 & 1.335 & 0.065 \\
\hline 11 & 1.058 & 0.053 & 0.152 & 0 & 0.794 & 0.054 & 0.904 & 0.063 & 1.333 & 0.044 \\
\hline 12 & 1.056 & 0.036 & 0.152 & 0 & 0.792 & 0.037 & 0.903 & 0.044 & 1.332 & 0.029 \\
\hline
\end{tabular}

\section{Conclusions}

To 2 - 5 step MF-DFA, generalized Hurst coefficient $h(q)$ of main channel's three stations and the north and south branch stations' daily runoff process is all not a constant in Weihe River, and all changes along with the change of $q, h(q)$ displays as a digression function of $q$. These disclosed that the daily runoff process of Weihe River's main channel and braches all have characteristic of multiple fractals.

At the main channel of Weihe River, fluctuation of the daily runoff process of upstream Lingjiacun station is stronger than downstream station, Xianyang station. At the same time, daily runoff series' fluctuation property of branches in north is stronger than that branch in south obviously. 
Runoff series' multiple fractal intensity of downstream Xianyang station is bigger than upstream Lingiiacun station, it means that Lingiacun station's daily runoff series meet more external factors' influence. The reason lies in that, between Linjiacun and Xianyang station, the runoff process affected seriously by water income and human activity, causes a fierce runoff fluctuation. But, situation goes to another side at downstream Huaxian station, here runoff fluctuation shows a weak fluctuation compared with Linjiacun and Xianyang station, the reason is this station situated at the downstream of Weihe River's main channel, in a larger catchment area, regional rainfall, more evaporation, more branches' flow converge and human activity, these factors superimpose and pin down mutually, cause the runoff process to tend to be steadily, fluctuation decreases on the contrary.

For same reason, runoff series' multiple fractal intensity of Zhangjiashan and Zhuangtou-two tributary stations is greater than that of Yingge station, just because two former stations' catchment area is bigger, its runoff influence factors are more than Yingge station's, but still in a limiting score; although we still can't tell what it is, Yinngge station's drainage area is small, its runoff effects factors have less opportunity to counterbalance mutually, so the runoff fluctuation is fierce.

\section{Acknowledgements}

The authors thank Zhou Xu for assistance with processing of data. The research was supported by Chinese National Natural Sciences Fund Project (51179160).

\section{Conflicts of Interest}

The authors declare no conflicts of interest regarding the publication of this paper.

\section{References}

[1] GuPta, V.K. and Waymire, E. (1990) Multiscaling Properties of Spatial Rainfall and River Flow Distributions. Journal of Geophysical Research, 95, 1999-2009. https://doi.org/10.1029/JD095iD03p01999

[2] Bates, B.C., Rahman, A., Mein, R.G. and Wienmann, P.E. (1998) Climate and Physical Factors That Influence the Homogeneity of Regional Floods in Southeastern Australia. Water Resources Research, 34, 3369-3381. https://doi.org/10.1029/98WR02521

[3] Robison, J.S. and Sivapalan, M. (1997) An Investigation into the Physical Causes of Scaling and Heterogeneity of Regional Flood Frequency. Water Resources Research, 33, 1045-1059. https://doi.org/10.1029/97WR00044

[4] Fu, J. and Ding, J. (1995) The Preliminary Study on the Fractal Dimension of Flow Hydrograph and Basin Configuration in Jialing River. Journal of Chengdu University of Science and Technology, No. 1, 74-79.

[5] Wang, W.S. and Xiang, H.L. (2005) A Study of Runoff Dimensions Based on Continuous Wavelet Transformation. Journal of Hydraulic Engineering, 36, 598-601.

[6] Ding, J. and Liu, G.D. (1999) Fractal Dimension Estimation of Daily Runoff Process. 
Hydraulic Power of Sichuan, 18, 74-76.

[7] Li, X.B. and Ding, J. (1999) The Wavelet Estimation of Hydrologic Time Series. Advances in Water Science, 10, 1-6.

[8] Liu, X.-P., Zhou, Y.-W. and Gan, Y.-P. (2004) Study on Fractal Characteristics of Daily Wastewater Flow Series. China Water \& Wastewater, 20, 53-55.

[9] Yu, S.M., Liu, G.D. and Wu, Y. (2005) The Fractal Analysis of the Stream Flow Hydrographs and Ecological Vulnerability in the Upper Reaches of Minjiang River. Journal of Southwest Nationality University, 31, 79-84.

[10] Chen, L.J. and Feng, L.H. (2006) Research on Relationship between Soil Erosion and Daily Runoff Process's Fractal in Malianhe River Watershed. Transactions of Northwest Forestry College, No. 5, 11-13.

[11] Yan, A.L. (2007) Research on Fractal Characteristics of the Stream Flow Time Series. Doctoral Dissertation, Xi'an Technology University, Xi'an.

[12] Chen, Y., Xu, Y.-P., Yin, Y.-X. and Liu, X.-C. (2008) Multifractal Characteristics of Daily Discharge Series in the Yangtze River. Geographical Research, 27, 819-828.

[13] Chang, F.X. (2011) Utilization of Fractal Theory on Water Resource and Hydrology. Doctoral Dissertation, Sichuan University, Chengdu.

[14] Yan, B.W., Li, Y., Feng, X.Q. and Fang, L. (2011) Spatial Variation Characteristic Research of Water Resource in Weihe Watershed. Pub. House of Water Conservancy of Yellow River, Zhengzhou.

[15] Peng, C.K. and Buldyrev, S.V. (1994) Mosaic Organization of DNA Nucleotides. Physical Review E, 49, 1685-1689. https://doi.org/10.1103/PhysRevE.49.1685

[16] Kantelhardta, J.W. and Zschiegner, S.A. (2002) Multifractal Detrended Fluctuation Analysis of Nonstationary Time Series. Physica A, 316, 87-114. https://doi.org/10.1016/S0378-4371(02)01383-3

[17] Yuan, Y. and Zhuang, X.T. (2007) Multifractal Detrended Fluctuation Analysis of International Exchange Rates. Journal of Management Sciences, 20, 80-85.

[18] Xie, X.H. and Cui, Y.L. (2008) Long-Term Correlation and Multi-Fractality of Reference Crop Evapotranspiration Time Series. Journal of Hydraulic Engineering, 39, 1326-1333. 